\title{
Teachers' Adequacy of Subject Knowledge in Primary Science: Assessing constructivist approaches from a sociocultural perspective
}

Anna Traianou, Goldsmiths, UK

\begin{abstract}
In recent years, increasing emphasis has come to be placed, both by researchers and by policy-makers, on the adequacy of primary teachers' subject knowledge of science. Within research, this emphasis has been linked to the rise of constructivist ideas about the significance of establishing children's prior conceptions of scientific concepts for effective teaching. In this article I examine two constructivist approaches to teachers' adequacy of subject knowledge within UK research on primary science education. In each case I provide a critique of the assumptions they make about the nature of knowledge and how it develops. I do this from a sociocultural perspective, which views knowledge and learning as necessarily situated within communities of practice. My aim is to assess the implications of this perspective for understanding teachers' adequacy of subject knowledge.
\end{abstract}

\section{Introduction}

Over the past 20 years there has been increased emphasis on the importance of subject knowledge as a component of teacher expertise. This is particularly true in the field of primary science education (see, e.g., Harlen, 1996; Summers, 1994; Summers, Kruger, \& Mant, 1997a). From this point of view, the effective teaching of primary science depends on the adequacy of teachers' understanding both of scientific knowledge and of the ways in which this knowledge can be taught successfully to children.

This stress on subject knowledge arose, to some extent, from the growing influence of constructivist perspectives about learning and teaching. These perspectives emphasize the importance of establishing learners' prior conceptions about the phenomena being studied and the need for teachers to challenge these everyday conceptions directly, so as to help pupils acquire understanding of scientific concepts (see, e.g., Driver, 1984; Driver \& Oldham, 1986; Harlen \& Osborne, 1985; Summers, 1994). It is argued that, in order to 
be able to do this, teachers must have sound science subject knowledge and an appropriate understanding of constructivist theories of learning.

During the 1990s, on the basis of this perspective, research was carried out into teachers' understanding of the scientific knowledge that was included in the newly introduced UK Primary Science National Curriculum (e.g., Harlen \& Holroyd, 1995, 1996; Kruger, Palacio, \& Summers, 1990; Kruger \& Summers, 1989; Summers \& Kruger, 1990; Summers \& Mant, 1995), and specific professional development projects were established aimed at helping teachers acquire the necessary evidence base (see, e.g., SPACE, 19871990; Summers, Kruger, \& Mant, 1997a, b).

In discussing teachers' adequacy of subject knowledge in science what is often implied is that, in order to be effective, a primary teacher must have a level of subject knowledge above some specified threshold. This has been suggested by Harlen (2000), for example, who argues that teachers need to have a "foundation for building a framework for teaching science" (p. 7). However, among researchers in primary science education there are different views about what this foundation should consist of, which are shaped by different interpretations of constructivism. Indeed, it is possible to identify two constructivist views about teacher expertise, which treat subject knowledge both in some similar and in some distinctive ways. Thus, for one group of researchers, those who I will refer to as "small range" constructivists, the foundation of teachers' knowledge should consist of teachers' adequate conceptual understanding of a small range of science concepts included in the UK National Curriculum (Summers et al., 1997a, b; Summers \& Mant, 1995, 1998).1 For another group of researchers, those whom I call "big ideas" constructivists, this foundation should take the form of adequate conceptual understanding of broad scientific principles, along with understanding of the nature of a proper scientific orientation (Harlen, 1999, 2000; Harlen \& Holroyd, 1995, 1996).

In this article I will examine in detail the assumptions about the nature of knowledge and how it develops that underpin these two constructivist views. I will do this from the perspective of a rather different-sociocultural-approach to understanding knowledge and learning. This third perspective stresses the complex interdependence of knowledge and action, and argues that knowledge and understanding are necessarily situated within the specific activities of communities of practice (se, e.g., Lave, 1988; Lave \& Wenger, 
1991; Wenger, 1998). My aim is to provide a critical analysis of the two main constructivist lines of thinking that have been used within UK research in primary science education, and to compare their implications for notions of teacher expertise with those of a sociocultural perspective.

\section{"Small Range" Constructivists}

"Small range" constructivists argue that there is a substantial lack of conceptual understanding among primary teachers about many areas of the UK Primary Science National Curriculum (e.g., Kruger et al., 1990; Summers \& Kruger, 1992), and that a considerable number of them experience great difficulty in acquiring the necessary scientific understanding (see, e.g., Summers, 1994).

On this basis, they argue that it may be unrealistic to expect primary teachers, especially those with no science qualifications, to acquire adequate conceptual understanding of all the concept areas included in the UK Primary Science National Curriculum (Summers \& Mant, 1998; see also Osborne \& Simon, 1996). And so these authors concentrate their efforts on defining a more limited range of significant science concepts that primary teachers need to understand and are capable of understanding. Summers and Mant, for example, discuss those aspects of the concept of energy that ought to be included in the UK Science National Curriculum, arguing that these should replace the ones concerned with balanced and unbalanced forces that many teachers find it difficult to understand (see also Summers, 1994). Such specific recommendations, as well as arguments about teachers' lack of scientific understanding, are based on research into teachers' responses to interviews and/or questionnaires; these often being administered before and after their participation in in-service education courses designed to help them acquire conceptual understanding of scientific concepts (see, e.g., Summers \& Mant, 1995).

"Small range" constructivists recognize that teachers are capable of constructing conceptual structures during their everyday interactions with aspects of the physical world, but they draw a sharp distinction between these everyday conceptualizations and sound scientific understanding (see, e.g., Summers, 1994). What is assumed here is that science involves a body of scientific propositions that have a precise and fixed meaning describing the universal properties present in all phenomena being described. By contrast, everyday 
conceptualizations are regarded as imprecise; they involve a variety of meanings or "intuitive beliefs" (Summers, 1994, p. 181), which are specific to the situations they describe. The term misconceptions is often used to describe those intuitive beliefs that are "at odds with the currently accepted view of the science community" (Kruger, Palacio, \& Summers, 1992, p. 341). Following on from this idea, "small range" constructivists stress that scientific understanding can only be ensured if teachers are introduced to the correct definition of specific scientific concepts during in-service education courses prior to their engagement with practical activities (e.g., Summers et al., 1997a, b; Summers \& Mant, 1995).

"Small range" constructivists give little emphasis to the development of teachers' problemsolving procedural understanding: their knowledge of the procedures needed to figure out what a scientific problem is about, and to collect and interpret evidence in order to address it. However, they are concerned with teachers' acquisition of practical skills, such as how to wire a circuit (see, e.g., Summers et al., 1997a). Indeed, they often imply that the development of problem-procedural knowledge follows automatically from the acquisition of simple concepts and process skills. Moreover, they suggest that scientific concepts can be broken down into smaller parts and taught to teachers separately. Summers and Mant (1998), for example, identify, in order of difficulty, seven "simple concepts" (p. 13) associated with aspects of electricity, which were easily understood by most primary teachers who participated in an in-service course on the topic. This points to a sequential view of knowledge acquisition on the part of these constructivists: the idea that simple concepts, facts, and process skills (lower functions of cognition) are basic in individuals' knowledge, and operate as prerequisites to learning higher-order forms of knowledge, such as complex concepts and problem-solving procedural knowledge (see Greeno, Pearson, \& Schoenfeld, 1999).

It is important to note here that the sequential view of knowledge acquisition is part of a broader psychological approach, often referred to as cognitivism (see Bredo, 1999). Cognitivism was developed in order to explain why students fail or succeed in acquiring academic knowledge (see Murphy, 1999). It uses computational methods and metaphors to model human learning and understanding, and is based on the assumption that there are certain universal features of human cognition (e.g., cognitive structures and short-term memory) that explain human learning in general. Moreover, it assumes that human 
thinking involves logical deduction using context-free rules. In particular, within this approach knowledge is seen as a property of the individual mind, acquired during the course of solving well-defined problems thrown up by the environment. 2 During this process, encoded symbols from the environment are stored in the individual's memory in hierarchical structures that stand in one-to-one correspondence with the problem in the world. From a sequential perspective, learners are expected to learn, first of all, the properties of the concepts of a discipline, and then the procedures by which such concepts are used to solve paradigmatic problems (see Watts, 1983). In turn, individuals' understanding of the properties of a specific scientific concept is assessed according to their ability to correctly classify instances as examples or non-examples of that concept (see Gagné, 1970; Klausmeier, Ghatala, \& Frayer, 1974).

This cognitivist view of knowledge underpins the methods used by "small range" constructivists to measure the adequacy of teachers' knowledge of specific scientific concepts. These are semi-structured interviews and multiple-choice questionnaires (see, e.g., Summers \& Kruger, 1992). The interviews are carried out with a small number of teachers using a deck of cards as a focus; the cards depicting events such as "a book lying on a table", or real objects such as a "jumping toy car" (Summers \& Kruger) and three-dimensional models (e.g., Mant \& Summers, 1995). These events are used to prompt discussion about a particular aspect of a situation, such as the role of energy (Summers \& Kruger). The interviews precede the questionnaires, which usually aim to establish the prevalence of misconceptions in a larger sample of teachers (e.g., Kruger et al., 1992; Summers \& Mant, 1995).3 Since the aim of such interviews and questionnaires is to identify teachers' existing knowledge, particular emphasis is placed on not helping teachers with their responses (e.g., Summers, Kruger, Mant, \& Childs, 1998).

The adequacy of teachers' science knowledge is determined by analysis of their responses to such interviews and questionnaires. It is assumed that their ability to classify correctly a limited number of instances associated with a particular concept, and to give reasons for their decisions in terms of a predefined explanation, indicates the adequacy of their understanding: interpreted as their capacity to use the same concept in the future. In evaluating this first type of constructivism, a key issue for consideration is whether adequacy of knowledge measured by interviews and questionnaires actually captures teachers' practical science expertise. 
As already noted, for "small ideas" constructivism teachers' ability to explain experience correctly is a matter of their matching the properties and relationships specified in a set of sentences with the properties and relationships present in the instances being described. There is a tacit belief here in representationalism, the idea that symbols mirror reality (see Bredo, 1999). Yet a belief in representationalism could only be sustained if each scientific concept gathered together identical instances or at least very similar ones (Barnes, 1982). Under such conditions, the application of such concepts would be unproblematic, and their involvement in science generalizations could make the application of other terms straightforward. For example, the statement that a force is a pull or a push could be used to provide a precise and adequate explanation of all the instances associated with force, if it could be asserted that the instances associated with the terms pull or push are identical (the extension of the concept). In such a case, of course, the extension only needs to include one instance that could be the very idea of "force", "pull", and "push". This suggests an essentialist account of concept application. However, in practice, instances of scientific concepts are not identical. For all the complexity of language, experience is much more complex and richer in information. Physical objects and events are never selfevidently identical with one another or possessed of a common essence (see Barnes, $1974,1982)$. Given this, teachers' ability to make sense of experience is a much more complex matter than a cognitivist view of mind allows; it is fraught with ambiguity and uncertainty (see Bruner, 1986). Responding to a situation involves exercising judgements about which concept is applicable in the particular situation, judgements that are often influenced by teachers' perceptions and interpretations of the specifics of the situation and that cannot be easily codified or made entirely explicit.

Following on from this, uncertainty or even failure in the task situation does not necessarily indicate lack of expertise on the part of teachers because understanding takes place over time and in context, rather than necessarily occurring at a fixed and predictable point. Indeed, some researchers argue that, given the dynamic nature of cognition, interviews "can only provide clues to ongoing cognitive processes" (Welzel \& Roth, 1998, p. 40; see also Roth, 1996). Teachers may fail to respond adequately to interview and questionnaire demands, but reconstruct their understanding in a more scientific direction as they reflect on the problem later. 
Finally, unlike the problems dealt with in interviews and questionnaires, those faced by teachers in classrooms may not be well defined and therefore will need to be actively framed as problems before they are solved. Children's questions and ideas about scientific concepts and phenomena may be expressed within contexts that are far more ambiguous and complex than the instances to which teachers are asked to respond in constructivist research. Given this, in order for teachers to deal with such cases they may need to figure out the nature of the situation first, before they decide which concept is the most appropriate to use (see Bruner, 1986; Greeno et al., 1999). Figuring out the situation may include framing and reframing the problem depicted in an instance, and trying out a number of different concepts to explain it, testing hypotheses, discussing the instance with the children in the classroom, or reading about specific concepts in resource books. In doing this, teachers may need the problem-solving procedural knowledge of science to which "small range" constructivism gives little emphasis. Moreover, decisions about how to respond to situations that arise during teaching are often made on the spot, which heightens the need for contextual judgement and teachers' reliance on their pedagogical expertise. However, the courses based on this approach do not introduce teachers to ways of thinking about ill-defined problems or pedagogical strategies for dealing with such problem situations.

It can be suggested, therefore, that even if a range of science concepts can be defined that primary teachers are able to apply correctly in explaining a limited number of situations associated with them, this still leaves open the possibility that teachers may not be able to apply the same concepts successfully in all future situations. In other words, in some situations teachers may still express misconceptions about concepts they previously appeared to understand adequately.

In summary, there are some serious questions to be raised about this way of approaching teachers' adequacy of subject knowledge in primary science. Some of these concern the assumptions about the nature of knowledge, and about teachers' development of scientific understanding. Others relate to the methods used to measure the adequacy of teachers' understanding. Above all, there are significant questions about the relationship between the understanding that teachers display in interviews and questionnaires and their practical expertise: their ability to use scientific knowledge in classroom situations. 


\section{"Big Ideas" Constructivists}

A second group of researchers in primary science education, those whom I called 'big ideas" constructivists, argue that the subject knowledge that primary teachers need to possess in order to teach science effectively consists of conceptual understanding of a small number of broad scientific principles (the "Big Ideas of Science"), along with procedural understanding characteristic of a proper scientific orientation (Harlen, 1999, 2000; Harlen \& Holroyd, 1995, 1996).4 Discussing the importance of teachers' conceptual understanding of the "Big Ideas of Science", Harlen (1997) says:

Why "big ideas"? Because these are, in the end, what we want children to understand - not particular muscles in the arm, not the particular position of that image in the plain mirror, but the general ideas that help to explain muscle action wherever it happens and all the phenomena where images are formed. (p. 7)

In turn, the necessary procedural understanding involves understanding how science begins with observation, and raising questions about what has been observed, and proceeds through predictions and hypothesizing, planning and carrying out an investigation, and collecting and interpreting data (see, e.g., Harlen, 2000).

"Big ideas" constructivists believe that the understanding of science develops as individuals interact with their own experience and with the ideas of others, and involves conceptual change (see Harlen, 1999). On such a view, procedural understanding is the means for acquiring conceptual understanding. In other words, knowledge of how to do science develops interactively with knowledge of the concepts of science. So, this approach to teachers' subject knowledge places emphasis on problem-solving aspects of procedural knowledge, which "small range" constructivists consider higher order and perhaps beyond the reach of many primary teachers.

Another difference is that, while "small range" constructivists draw a sharp distinction between teachers' everyday conceptualizations of physical phenomena and scientific concepts, "big ideas" constructivists argue that there are similarities between these; and that teachers' misunderstandings can be seen as resulting from their making inappropriate links between experience and knowledge or from use of misleading everyday language. Moreover, these constructivists argue that it is possible to foster and develop further teachers' ability to test their ideas against evidence, to the point that it takes the form of 
scientific inquiry, thereby helping them to make appropriate links between knowledge and experience. Influenced by Vygotsky's work, this group of researchers also emphasizes the role of social interaction with more knowledgeable others in the development of scientific understanding (see Harlen, 1996; Harlen \& Holroyd, 1995, 1996).

Following on from this, "big ideas" constructivists stress that, although some scientific ideas are more difficult for teachers to understand than others, "given the opportunity, teachers can come to a scientific view of many things, linking up their existing experience, using their common sense" (Harlen, 2000, p. 229). In turn, they describe teachers' knowledge of science as a network of links between scientific concepts and experience, which can be extended as they make new links between scientific concepts and ways of interpreting evidence. Thus, developing procedural understanding is seen as the key to educating primary science practitioners. This is not just because this understanding is fundamental in helping teachers acquire conceptual knowledge of the "Big Ideas of Science", but also because it is closely related to the ways in which teachers should help children develop their own scientific understanding in the classroom (see, e.g., Harlen, 1999, 2000).

Like the first type of constructivism, "big ideas" constructivists also use interviews to determine teachers' adequacy of scientific understanding. Teachers are presented with events (e.g., those produced by a battery-operated circuit that includes a switch and a bulb) that are associated with specific scientific ideas (e.g., "current flow needs a circuit of suitable materials"). During interviews the teachers are asked to discuss the particular event and to arrive at a "collaborative explanation" (Harlen, 1996, p. 6) for the event; in other words, an explanation that is satisfactory for both the teacher and the interviewer. Thus, the interviewer might direct teachers' attention to problem-solving aspects of an event, and/or suggest to them ideas to test out. And, in doing this the interviews may provide a model that facilitates teachers' procedural understanding.

Helping teachers in developing their explanations differentiates this approach from the previous one, in which teachers are not offered any kind of support in the interviews or questionnaires. For "big ideas" constructivists this kind of support is judged to be appropriate because what is taken as teachers' knowledge is not the knowledge that 
teachers appear already to possess, but the understanding they are capable of achieving under the guidance of another more knowledgeable person.

Despite these important differences, this approach to teachers' expertise, like the first, treats knowledge from a cognitivist perspective. It seems to be assumed, for example, that once teachers have achieved a collaborative explanation for a particular event, they have acquired adequate knowledge for applying the concept in the future, both in the classroom and in other contexts. Indeed, doubts that might surround the interpretation of problemsolving situations seem only to be treated as acceptable during teachers' acquisition of subject knowledge. These are not regarded as a significant part of teachers' responses to situations that arise during teaching, at least not when they relate to a concept of which teachers have already been shown to possess adequate understanding. Instead, it is expected that such problem-solving situations are well defined, and that they can be resolved either by the retrieval of the correct "Big Idea of Science" or by the application of a clearly defined scientific procedure.

What I am arguing, then, is that, despite their important differences, the two constructivist approaches to teachers' subject knowledge I have discussed share some limitations in common, especially in terms of their interpretation of the relation between teachers' knowledge and their classroom expertise. They assume a universalistic view of scientific knowledge: the idea that the concepts of science are abstract, precise entities that can be internalized by the individual teacher. Moreover, both approaches treat teachers' understanding as taking the form of acquired, commodity-like knowledge that is essentially decontextualized and available to be applied across situations. From their point of view, once primary teachers have acquired the correct understanding of scientific concepts and/or of scientific procedures, they should be able to apply them in the future, both in classrooms and in other situations.

My questioning of these assumptions is based on some recent developments in the study of cognition. These emphasize that the construction of knowledge cannot be seen as independent of the situation in which it occurs. A sociocultural approach to cognition offers a rather different picture of knowledge, understanding, and learning-one that has important implications for how teachers' adequacy of science knowledge might be defined, and for how it relates to classroom practice. 


\section{Sociocultural Approaches to Knowledge and Understanding}

Unlike cognitivist approaches to mind, which treat the concepts and ideas expressed in language as representing the situations they describe-and, therefore, as having an existence independent from the situation in which they were produced-sociocultural theories view the concepts and ideas expressed in language as the products of a particular line of activity that take their meaning from the context of that activity (e.g., Brown \& Palinscar, 1989; Collins, Brown, \& Newman, 1989; Newman, Griffin, \& Cole, 1989; Wertsch, 1985).

Like "big ideas" constructivists, they draw on Vygotsky's work, but this time in treating language as providing the means or tools for social coordination and adaptation (see Brown, Collins, \& Duguid, 1989; Putman \& Borko, 2000). Throughout their lives, individuals participate in various communities of practice, ranging from scholarly disciplines such as science or history to groups of people sharing a common interest, including those operating in particular classrooms. Each of these communities generates tools, a set of shared social meanings, which its members use to interpret and negotiate their interpretations with one another, thereby enabling them to continue to act successfully in the activities of that community. In the course of this process, people develop, often tacitly, rich networks of links between specific tools and situations, which are employed to make sense of future situations. And because situations are not fixed or identical, each time an individual uses a tool to construct understanding of a new situation that resembles an old one, he/she develops a better understanding of both the tool and the situation itself. As Brown et al. put it:

People who use tools actively rather than just acquire them build an increasingly rich implicit understanding of the world in which they use the tools and of the tools themselves. The understanding, both of the world and of the tool, continually changes as a result of their interaction. (1989, p. 33)

Thus, from a sociocultural perspective, an individual's understanding of the concepts, theories, and ideas of a particular community is a dynamic process resulting from acting in situations and from negotiating with other members of that community. Furthermore, such understanding is constructed first on a social plane before it becomes internalized by the 
individual, and is best described as an "evolving spiral" (Murphy, personal communication), in which lower mental functions (e.g., concepts and facts, and simple process skills) and higher mental functions (problem-solving procedural knowledge, complex concepts, perception, remembering, etc.) develop interdependently as individuals participate in socially and culturally organized activities.

This is a very different approach from treating understanding as involving the application of a static set of concepts and procedures, as within cognitivist perspectives (Bredo, 1997, 1999). For sociocultural theorists, the activity becomes the unit of analysis rather than the individual's mental structures. Indeed, they stress that individual actions and mental representations are only understandable as integral elements of the activity systems in which they function, and which they in turn constitute (e.g., Engestörm, 1988).

Following on from this, sociocultural theorists emphasize the ambiguity and contingency of understanding. They argue that knowledge is organized for a particular task; it can never be sufficiently detailed and precise to anticipate exactly the conditions of future action, but, rather, the individual must be prepared to deal with uncertainty. As Keller and Keller (1993) put it:

An individual's knowledge is simultaneously to be regarded as representational and emergent, prepatterned and aimed at coming to terms with actions and products that go beyond the already known. (p. 127)

Aside from offering a different perspective about knowledge and how it develops, sociocultural theory also carries particular implications about learning and expertise. It suggests that learning involves enculturating novices into the practices of a particular community where they learn through cognitive apprenticeship its language, and other cultural patterns of communication, as well as how to make decisions about which conceptual and procedural tools to use in order to solve well-defined and ill-defined problems of their community (e.g., Brown et al., 1989; Cobb, 1994; Lave \& Wenger, 1991; Rogoff, 1994; Roth, 1995). On this view, the "master" or expert is relatively more skilled than the novice in terms of having a broader understanding of the important features of a cultural activity. However, the expert's depth and breadth of understanding is still developing in the process of carrying out the activity and in deciding which tools to use in order to guide others successfully in it (see Rogoff, 1990). Thus, the essence of an 
individual's expertise is its functionality: the ability to employ knowledge as a resource in order to pursue situated, contextualized goals emanating from problem-solving situations in specific communities of practice (see Greeno et al., 1999).

It is important to note here that, like constructivist perspectives, sociocultural theorists also emphasize the crucial function that knowledge plays in practice (see Edwards, 2005; Tobin, 1998). However, given that sociocultural theorists recognize the essential and inseparable roles of cultural tools, social activity, and individual efforts, they argue that the assessment of an individual's knowledge should be based on how this person performs, and not on what this person says about his/her own performance or on what he/she can and cannot do in artificial situations (see Rogoff, 1990; Roth, 1999).

This last point has particular implications for assessing primary teachers' adequacy of science subject knowledge, since it directs our attention to the study of teachers' performance in the activities of their communities of practice. Also, teachers can be seen as participating in a variety of communities of practice, such as those formed by staff in a particular school, those made up of teachers and mentors in initial teacher education and continuing professional development courses, and those constituted by their interacting with children in particular classrooms. In turn, the nature of the problem situations with which teachers deal depends on their context, and different problems require different kinds of solution, which in turn require differential use of cultural tools. On this view, teachers' adequacy of subject knowledge is a complicated issue that involves assessing their use, and limitations on their use, of cultural tools in relation to particular tasks in particular contexts.

In other words, a sociocultural approach to teacher expertise also carries some methodological implications. It suggests that this needs to be investigated in action; in the perspectives and performances of those who are recognized as experts in their local communities of practice. Rather than relying on semi-structured interviews and questionnaires to assess the knowledge that teachers possess, sociocultural perspectives indicate a need to make use of the qualitative methodological traditions that have been developed in anthropology and sociology, in which participant observation and in-depth interviewing are employed to understand what people do in everyday situations, and how 
their perspectives on the world are implicated in their activities (e.g., Denzin \& Lincoln, 1994; Guile \& Young, 1998; Lave, 1988; Lave \& Wenger, 1991; Wenger, 1998).

Only a small amount of research has been carried out in science education adopting a sociocultural approach (Rosebery, 1998; Rosebery, \& Puttick, 1998; Traianou, 2003; Traianou, 2006; Warren \& Rosebery, 1996). Rosebery and Puttick carried out a study of 14 newly qualified elementary teachers who were not science specialists. The focus was on the ways in which they developed their understanding of science and the teaching of science during the first 4 years of their teaching. This study, which was part of a large professional development project, was framed by the assumption that, in expert teaching, uncertainty and how one deals with it plays as important a role as the certainty that derives from accumulated knowledge and experience. Thus, during the teachers' learning about science and the teaching of science, the researchers sought to foster a culture where instances of not knowing were given equal status to instances of knowing (see also Ball, 1998; Duckworth, 1987).

As learners of science, teachers were asked to carry out investigations in areas such as motion and acceleration, and buoyancy and density. These investigations were often initiated by the teachers' own questions about a phenomenon. They were conducted in small groups to enable them to become engaged in debate with colleagues about their existing ideas as well as about current scientific explanations and theories. During this, they were encouraged to ask, and seek answers to their own questions; to explore problems and resources; to collect, analyse, and interpret data; to construct, juxtapose, and interpret graphical representations; to compare their methods and results with those of others; and to use the theories of others, including the standard explanations of science, as tools in their work. Teachers were encouraged to keep diaries about significant aspects of their learning, including any confusions or dilemmas that occurred during their process of learning science and how they went about resolving them. In turn, selected episodes of their learning were often discussed with other colleagues and the researchers during unstructured interviews.

As teachers of science, participants examined videotaped episodes of science lessons from their own classrooms and explored dilemmas and confusion they had about their students' learning, their practice, and curricula. These included questions about the 
language the students used and what they did during a science activity as well as what could be learned from these about children's science thinking and learning. To respond to such questions, teachers were expected and encouraged to draw upon multiple resources, including their own understanding of the phenomenon under study, their knowledge of individual children, their own understanding of learning and teaching, as well as their pedagogical understanding.

One important finding from this study is that teachers' science subject knowledge develops over time in contingent ways, and facilitating this requires offering them opportunities not only to get deeply engaged with complex scientific ideas, theories, and practices, but also to reflect on and think through ways of employing cultural tools to deal with well-defined and ill-defined problem situations. Moreover, it is argued that the development of teachers' understanding of science cannot be easily separated from their understanding of pedagogy. It was often found, for example, that during both the teachers' inquiries in science and their inquiries in teaching and learning, discussion of scientific ideas on the one hand and discussion about children's learning and pedagogical practice on the other occurred simultaneously. Indeed, as teachers participated in their own scientific activity they found themselves questioning how they might teach a scientific phenomenon such as acceleration to children. Similarly, in analysing aspects of their teaching, they questioned their own understanding of a particular scientific phenomenon. For instance, as one teacher considered her students' explanation that "air" was what allowed a big, heavy boat to float, she probed her own understanding of density and the role it played in buoyancy. This led her to further explore the complex ideas that explain flotation as well as to question and develop her own pedagogical practices. As teachers were gaining more experience in learning about and teaching science, they became more capable in using creatively cultural tools both in terms of developing their own learning of science and in developing their pedagogy and classroom practices.

Similar findings have been reported in an in-depth study of one expert primary science practitioner (for a detailed description of this study, see Traianou, 2003; Traianou, 2006). Here, data were used from unstructured interviews, email messages, the teacher's own writing, and classroom observation to portray the teacher's views about her own subject knowledge and the role it plays in her teaching, her beliefs about the learning and teaching of science, and her practice. One outcome of this study is that teacher expertise 
is eclectic in character, drawing on a variety of pedagogical strategies and theories of learning in dealing with the contingent situations faced in the classroom. Subject knowledge plays a significant role in helping teachers to interpret and act successfully in these situations and to deal with other tasks. Indeed, this study suggests that teachers' subject knowledge is functional, context specific, and integrated with features of the classroom situation or the task that teachers are aiming to accomplish. For example, the teacher in this study uses multiple ways of assessing her own understanding of science and diverse strategies for developing it further. Some of these relate to her ability to explain adequately to colleagues aspects of the scientific concepts that they have to teach and their responses to this. Equally important is a metacognitive awareness about the organization and synthesis of her scientific understanding. In other words, this teacher's expertise enables her to distinguish the aspects of scientific knowledge she understands from those that she does not grasp and develop these further. Her subject knowledge also helps her to plan learning objectives and practical activities, organize her teaching in an exploratory way, and recognize children's everyday ideas that are different from the current scientific knowledge. However, she emphasizes the contingency of her scientific understanding by arguing that providing explanations that arise during teaching and relating them to scientific concepts is not always a straightforward process, even when she has taught them before. As an example, she describes an episode that followed work with her Year 5 class (10-11 years old) about forces. In this episode she was discussing with the children the forces that act on a person on a floating boat when she found herself wondering about the possibility of the person on the boat being weightless. Situations like this often appear during her teaching and she has developed certain strategies for dealing with them, such as thinking about the problem alone, or engaging the children in the process by asking questions that aim to interpret and clarify the problem. In these ways, a solution to problems is sought, yet this simultaneously involves developing her own and the children's learning of a particular scientific concept. In this way, she develops a repertoire of ways of dealing with specific problem situations, which, in turn, she employs to respond to new situations that she sees as similar to and yet different from those experienced in the past. 


\section{Conclusion}

In this article, I have argued that there are some important differences between the two main constructivist lines of thinking about teacher expertise that have been influential within UK research on primary science education. These concern their interpretation of the relationship between conceptual and procedural knowledge, and of the role that social interaction plays in the construction of teachers' scientific understanding. These differences determine the kind and level of scientific understanding that primary teachers are judged to be capable of acquiring, and hence the foundation of their classroom expertise. Nevertheless, I have argued, both "small" and "big" ideas constructivism underestimate the complexity of practice. They treat the understanding that teachers display during semi-structured interviews and questionnaires as commodity-like knowledge that is available to be applied in future and classroom situations. And they assume that failure to display such understanding indicates an incapacity to teach the relevant scientific concepts in the classroom.

By contrast, sociocultural perspectives argue that knowledge is tied to action, and emphasize the idea that understanding is often messy and contingent, and depends upon processes of interpretation and negotiation in which the problem at hand and judgements about which cultural tool to use are recurrently formulated and reformulated. On this view, teachers' subject knowledge is a resource whose adequacy is determined by functionality; it must be judged in terms of teachers' ability to employ tools skilfully in order to achieve specific goals that emerge as they participate in the activities of various communities of practice in which they are involved, especially those that develop in classrooms.

It is important to note that a sociocultural perspective does not imply complete rejection of the methods used by constructivist research in assessing the adequacy of primary teachers' scientific understanding. However, it does suggest that the findings from this kind of research need to be treated with great caution, and that they should be supplemented by in-depth study of teachers' use of cultural tools in particular contexts, the limitations involved in their practice, and how these are related to the practical communities in which they participate. Research carried out following this approach suggests that expert teachers develop a dynamic repertoire of context-specific forms of knowledge that help them to see new situations as both similar and yet different from 
those encountered previously, and that it is only in this way that they learn more effective modes of practice.

\section{Notes}

1. The term conceptual understanding refers to the individual's ability to explain aspects of the physical world by identifying links among relevant "items" of knowledge (see Hiebert \& Lefevre, 1986).

2. A "well-defined" problem is a problem that has one correct solution.

3. Quite often, some of the instances used during the interviews are included in the questionnaire, together with a number of statements, from which the teachers are asked to choose whether they think the statement is true or false (and two more choices are included: "don't understand" and "not sure").

4. Examples of the "Big Ideas of Science" are "water exists as solid, liquid and gas" and "switches make and break the circuit" (Harlen, 1996, p. 6).

\section{References}

Ball, D. (1998). What do students know? Facing challenges of distance, context and desire in trying to hear children. In B. J. Biddle, T. L. Good, \& I. F. Goodson (Eds.), International handbook of teachers and teaching. Dordrecht, The Netherlands: Kluwer.

Barnes, B. (1974). Scientific knowledge and sociological theory. London: Routledge \& Kegan Paul.

Barnes, B. (1982). T. S. Kuhn and social science. London: Macmillan.

Bredo, E. (1997), The social construction of learning. In G. D. Phye (Ed.), Handbook of academic learning: Construction of knowledge. CA: Academic Press.

Bredo, E. (1999). Reconstructing educational psychology. In P. Murphy (Ed.), Learners, learning \& assessment. London: Paul Chapman Publishing.

Brown, A. L., \& Palinscar, A. S. (1989). Guided, cooperative learning and individual knowledge acquisition. In L. B. Resnick (Ed.), Knowing, learning and instruction. Hillsdale, NJ: Lawrence Erlbaum Associates. Brown, J. S., Collins, A., \& Duguid, P. (1989). Situated cognition and the culture of learning.

Educational Researcher, January-February, 32-42.

Bruner, J. (1986). Actual minds, possible worlds. Cambridge, MA: Harvard University Press.

Cobb, P. (1994). Where is the mind? Constructivist and sociocultural perspectives on mathematical development. Educational Researcher, 23(7), 13-20.

Collins, A., Brown, J. S., \& Newman, S. E. (1989). Cognitive apprenticeship: Teaching the crafts of reading, writing, and mathematics. In L. B. Resnick (Ed.), Knowing, learning, and instruction. Hillsdale, NJ: Lawrence Erlbaum Associates.

Denzin, N. K., \& Lincoln, Y. S. (Eds.). (1994). Handbook of qualitative research. Thousand Oaks, CA: Sage. Driver, R. (1984). A review of research into children's thinking and learning in science. In B. Bell, W. Watts, \& K. Ellington (Eds.), Learning, doing and understanding in science: The proceedings of a conference. London: Woolley Hall.

Driver, R., \& Oldham, V. (1986) A constructivist approach to curriculum development in science. Studies in Science Education, 13, 105-122. 
Duckworth, E. (1987). The having of wonderful ideas. New York: Teachers College Press.

Edwards, A. (2005). Let's get beyond community and practice: the many meanings of learning by participating. The Curriculum Journal, 16(1), 49-65.

Engestörm, Y. (1988). How to do research on activity? The Quarterly Newsletter of the Laboratory of Comparative Human Cognition, 10(2), 30-31.

Gagné, R. M. (1970). The conditions of learning. New York: Rinehart \& Winston.

Greeno, J. G., Pearson, P. D., \& Schoenfeld, A. H. (1999). Achievement and theories of knowing and learning. In R. McCormick \& C. Paechter (Eds.), Learning and knowledge. London: Paul Chapman Publishing.

Guile, D., \& Young, M. (1998). Apprenticeship as a conceptual basis for a social theory of learning, Journal of Vocational Education and Training, 50(2), 173-192.

Harlen, W. (1996). Primary teachers' understanding of science and its impact in the classroom. Paper presented at The British Educational Research Association, Lancaster.

Harlen, W. (1997). Teachers' subject knowledge and understanding and the teaching of science at the primary level. Science Teacher Education, 19, 6-7.

Harlen, W. (1999). Effective teaching of science: A review of research. Edinburgh, Scotland: The Scottish Council for Research in Education.

Harlen, W. (2000). The teaching of science in primary schools. London: David Fulton Publishers.

Harlen, W., \& Holroyd, C. (1995). Primary teachers' understanding of concepts in science and technology.

Edinburgh, Scotland: The Scottish Council for Research in Education.

Harlen, W. \& Holroyd, C. (1996). Primary teachers' understanding of concepts in science: impact on confidence and teaching. International Journal of Science Education, 19(1), 93-105.

Harlen, W., \& Osborne, R. (1985). A model for learning and teaching applied to primary science. Journal of Curriculum Studies, 17(2), 133-146.

Hiebert, J., \& Lefevre, P. (1986). Conceptual and procedural knowledge in mathematics: an introductory analysis. In J. Hiebert (Ed.), Conceptual and procedural knowledge: The case of mathematics. London: Lawrence Erlbaum Associates.

Keller, C., \& Keller, J. D. (1993). Thinking and acting with iron. In S. Chaiklin \& J. Lave (Eds.), Understanding practice. Cambridge, England: Cambridge University Press.

Klausmeier, J. H., Ghatala, E. S., \& Frayer, D. A. (1974). Conceptual learning and development-A cognitive view. New York: Academic Press.

Kruger, C., Palacio, D., \& Summers, M. (1990). A survey of primary school teachers' conceptions of force and motion. Educational Researcher, 32(2), 83-95.

Kruger, C., Palacio, D., \& Summers, M. (1992). Surveys of English primary school teachers' conceptions of force, energy and materials. Science Education, 76, 339-351.

Kruger, C., \& Summers, M. (1989). An investigation of some primary teachers' understanding of changes in materials. School Science Review, 71(255), 17-27.

Lave, J. (1988). Cognition in practice: Mind, mathematics, and culture in everyday life. Cambridge, England: Cambridge University Press. 
Lave, J., \& Wenger, E. (1991). Situated learning: Legitimate peripheral participation. Cambridge, England: Cambridge University Press.

Mant, J., \& Summers, M. (1995). Some primary-school teachers' understanding of the Earth's place in the Universe. Research Papers in Education, 10(1), 101-129.

Murphy, P. (1999). Supporting collaborative learning: a gender dimension. In P. Murphy (Ed.), Learners, learning, and assessment. London: Paul Chapman Publishing.

Newman, D., Griffin, P., \& Cole, M. (1989). The construction zone: Working for cognitive change in school. Cambridge, England: Cambridge University Press.

Osborne, J., \& Simon, S. (1996). Primary science: Past and future directions. Studies in Science Education, 26, 99-147.

Putman, R., \& Borko, H. (2000). What do new views of knowledge and thinking have to say about research on teacher learning? Educational Researcher, 29(1), 4-15.

Rogoff, B. (1990). Apprenticeship in thinking: Cognitive development in social context. Oxford, England: Oxford University Press.

Rogoff, B. (1994). Developing understanding of the idea of communities of learners. Mind, Culture, and Activity, 1, 209-229.

Rosebery, A. (1998). Investigating a teacher's questions through video. In A. Rosebery \& B. Warren (Eds.), Boats, balloons, and classroom video: Science teaching as inquiry. Portsmouth, NH: Heinemann.

Rosebery, A., \& Puttick, G. (1998). Teacher professional development as situated sense-making: A case study in science education. Science Education, 82, 649-677.

Roth, W.-M. (1995). Authentic school science. Boston, MA: Kluwer Academic Publishers.

Roth, W.-M. (1996). Art and artifact of children's designing: a situated cognition perspective. Journal of the Learning Sciences, 5, 129-166.

Roth, W.-M. (1999). Authentic school science: Intellectual traditions. In R. McCormick \& C. Paechter (Eds.), Learning and knowledge. London: Paul Chapman Publishing.

SPACE (1987-1990). Science processes and concept exploration (SPACE) project. University of London, King's College and University of Liverpool.

Summers, M. (1994). Science in the primary school: the problem of teachers' curricular expertise. The Curriculum Journal, 5(5), 179-193.

Summers, M., \& Kruger, C. (1990). Research into English primary school teachers' understanding of the concept of energy. In L. D. Newton (Ed.), Primary science: the challenge of the 1990s. Clevedon, England: Multilingual Matters.

Summers, M., \& Kruger, C. (1992). Research into English primary school teachers' understanding of the concept of energy. Evaluation and Research in Education, 6(2\&3), 95-111.

Summers, M., Kruger, C., \& Mant, J. (1997a). Teaching electricity effectively: A research-based guide for primary science. Hatfield, England: The Association for Science Education: Primary School Teachers and Science (PSTS) Project.

Summers, M., Kruger, C., \& Mant, J. (1997b). A particle approach to the teaching of electricity and simple circuits. Proceedings of the 3rd Summer Conference for Teacher Education in Primary Science: Developing the 'Right Kind of Teacher' in Primary Science. University of Durham, School of Education. 
Summers, M., Kruger, C., Mant, J., \& Childs, A. (1998). Developing primary teachers' understanding of energy efficiency. Educational Researcher, 40(3), 311-327.

Summers, M., \& Mant, J. (1995). A misconceived view of subject-matter knowledge in primary science education: a response to Golby et al. "Some researchers understanding of primary teaching". Research Papers in Education, 10(3), 303-307.

Summers, M., \& Mant, J. (1998). A view from the PSTS project. Primary Science Review, 52, 12-14.

Tobin, K. (1998). Sociocultural perspectives on the teaching and learning of science. In M. Larochelle, N.

Bednarz, \& J. Garrison (Eds.), Constructivism and education. Cambridge, England: Cambridge University Press.

Traianou, A. (2003). Understanding teacher expertise in primary science: A sociocultural approach. Unpublished Ph.D. thesis, The Open University, Faculty of Education and Language Studies.

Traianou, A. (2006). Understanding teacher expertise in primary science: a sociocultural approach. Rotterdam: SENSE Publishers.

Warren, B., \& Rosebery, A. (1996). This question is just too easy! Students' perspectives on accountability in science. In L. Schauble \& R. Glaser (Eds.), Innovations in learning: New environments for education.

Mahwah, NJ: Erlbaum.

Watts, M. (1983). A study of alternative frameworks in school science. Unpublished Ph.D. thesis, University of Surrey.

Welzel, M., \& Roth, W.-M. (1998). Do Interviews really assess students' knowledge? International Journal of Science Education, 20(1), 25-44.

Wenger, E. (1998). Communities of practice. learning, meaning, and identity. Cambridge, England:

Cambridge University Press.

Wertsch, L. S. (1985). Vygotsky and the social formation of mind. Cambridge, MA: Harvard University Press. 